\title{
Study of the Composition of the Volatile Fraction of the Pistacia lentiscus \\ Abdelkader $\mathbf{M}^{1 *}$, Bouyahia Naima $\mathrm{B}^{1}$ and Boudiaf Nassima $\mathrm{B}^{2}$
}

${ }^{1}$ Department of Chemistry, Faculty of Sciences, University Badji Mokhtar-Annaba, LM2 PM, BP 12 Campus, Sidi Amar, Algeria

${ }^{2}$ Faculty of Pharmacy de Annaba, LM2 PM, BP 12 Campus, Sidi Amar, Algeria

*Corresponding author: Abdelkader M, Department of Chemistry, Faculty of Sciences, University Badji Mokhtar-Annaba, LM2 PM, BP 12 Campus, Sidi Amar, Algeria, Tel: +213661718929; E-mail: mizi_Abdelkader@yahoo.fr

Received: August 16, 2017; Accepted: August 22, 2017; Published: August 28, 2017

Copyright: (c) 2017 Abdelkader M, et al. This is an open-access article distributed under the terms of the Creative Commons Attribution License, which permits unrestricted use, distribution, and reproduction in any medium, provided the original author and source are credited.

\begin{abstract}
In this work, the study of the composition of Pistacia lentiscus volatile fraction in El Kala region is targeted. The chromatographic analyses (CPG and CG-SM) of the Pistacia lentiscus extracts allowed to identify solvent, that is the hexane, thirty components, in which three of them are considered major 2-Methoxy,4-vinlphenole (36.5\%), 2,3dihydrobenzofuran $(25.50 \%)$. and phenyl ethanol (10.85\%) and thirty-six other components by the polar solvent with the DMSO as a major one, the oleamide $(26.07 \%)$.
\end{abstract}

Keywords: Volatile fraction; CPG; CG-SM; Pistacia lentiscus

\section{Introduction}

The Pistacia lentiscus is a shrub that can reach three meters of height that finds its roots in places like scrublands this dioecious plant belongs to the family of anacardium [1] and is distinguished by foliage compared to other pistachio trees. Several tests have been carried out on the oil extracted from the ripe fruit proving that it contains unsaturated and saturated fatty acids and vitamin [2,3]. However, our bibliographic research has shown that no study has been carried out on the basis of the determination of volatile scopes. We are interested in warring out this work to determine the chemical constituents of volatile fractions with the help of the CPG-MS technical.

\section{Materials and Methods}

\section{Materials and vegetal}

The conditions for harvesting the fruit are summarized in the Table 1 .

\begin{tabular}{|l|l|l|l|l|l|}
\hline Botanical Name & Date harvested & Lieu & Development Stage & Season & Middle vegetative \\
\hline Pistacia lentiscus & November 2016 & Oued Hout & Fruit ripe & rain & Forest \\
\hline
\end{tabular}

Table 1: Summary of harvest conditions.

The fruits are washed with distilled water to remove organisms responsible of the deterioration of their quality then they are immersed in nitrogen liquid for chemical and physical stabilization. The fruits are dried in an oven at $95^{\circ} \mathrm{C}$ for 8 hours and then ground with a coffee grinder to obtain a fine powder [3-5].

\section{Volatile extracts preparation}

The extraction of the volatile fraction on $160 \mathrm{~g}$ of powder has been realized by hydro distillation, using an apparatus of (Clevenger 1928) type, for 3 hours, in a liter of water within a balloon of 2 liters [6,7]. The balloon is surmounted by a column of $60 \mathrm{~cm}$ length, related in its turn to a refrigerant followed by liquid extraction-hydrolat liquidusing the hexane and the DMSO as solvents. The extraction output of these substances is less than $0.4 \%$.

\section{Chromatographic analysis}

The analyses were realized with a chromatograph (Agilent technologies 6890) enhanced with a flame ionization detector (FID) of a capillary column HPS $(30 \mathrm{~m} \times 0,32 \mathrm{~mm})$ film thickness $0.25 \mathrm{~mm})$ the helium is the vector gas. The injector temperature is $270^{\circ} \mathrm{C}$, and des detector one is $250^{\circ} \mathrm{C}$. The furnace temperature program consists of one isotherm at $80^{\circ} \mathrm{C} / \mathrm{min}$, followed by a temperature ramp of $5^{\circ}$ $\mathrm{C} / \mathrm{min}$ up to $310^{\circ} \mathrm{C}(2 \mathrm{~min})$ [8]. The injection is made by mode split less. The volume injected is $1 \mu \mathrm{l}$. The components identification was executed drawing on their indices of KOVATS (IK) and on gas phase coupled to mass spectrometry (CG-SM). The latter was made on a gas phase chromatograph of Agilent Technologies 6890 type, coupled to mass spectrometer Autospee M-610. The ionization mode is the electronic impact of $70 \mathrm{eV}$ and the detection is made by an HRMS analyzer (high resolution mass spectrometry) type E-B-E within the masses range of 50-800 $\mathrm{Da}$ [9].

The temperature programming is identical to the one used previously for the detection by FID and the injection is by mode split less. The apparatus is related to data processing system managing a mass spectral library NIST $98[10,11]$. The components identification is based on the comparison of their mass spectra (CPG-SM) respective to library spectra (NIST 98) and (Adams 1995) library. Ans also based on the indices calculation of Kovats, these indices of Kovats were calculated following the equation 1 after an analysis under the same conditions of the chromatography of alkane series. 
Citation: Abdelkader M, Bouyahia Naima B, Boudiaf Nassima B (2017) Study of the Composition of the Volatile Fraction of the Pistacia lentiscus.

Page 2 of 3

$I K=(100 \times n)+100 \times \frac{\left(\operatorname{tr}_{\mathrm{i}}-\operatorname{tr}_{\mathrm{n}}\right)}{\left(\operatorname{tr}_{\mathrm{n}-1}-\mathrm{tr}_{\mathrm{n}}\right)}$

$\operatorname{Tr}_{\mathrm{i}}=$ retention time of the volatile fraction compound

$\operatorname{Tr}_{\mathrm{n}}=$ retention time of the alkane at $\mathrm{n}$ carbon

$\operatorname{Tr}_{\mathrm{n}-1}=$ retention time of the next alkane

\section{Results and Discussion}

The results obtained (Table 2) by solvent hexane and DMSO show that there is a great diversity of the chemical constituents of qualitative and quantitative aspects of the composition of the volatile liquor contains alcohols, aldehydes, ketones, nitrogen compound and furanic derivatives.

On the one hand, in the hexane extract, thirty components chemical reaction with a predominance of alcohol with 2-methoxyphenol vinyl chloride (36.51) and then the 2,3 dehydrobenzofuran, $25.50 \%$ followed of the phenyl ethanol $(10.85 \%)$ on the other hand the monoterpene compounds and oxygenated monoterpenes are found in large quantities on the other hand the DMSO extract, thirty-six compounds, aldehydes and ketones such as verlanone (1.27\%), the range dicatactnoe $(0.45 \%)$ vanilla $(3.16 \%)$ and also the alcohols (borneol, eugenol) the terpene compounds are present in small quantities.

\begin{tabular}{|c|c|c|c|}
\hline Compound & $\mathbf{R} \mathbf{I}$ & Hexane (\%) & DMSO (\%) \\
\hline 2-Ethylhexanol & 1038 & 1.45 & 1.28 \\
\hline Eucalyptole & 1045 & 1.10 & - \\
\hline 2,3 dihydrolenzofurane & 1050 & 25.50 & - \\
\hline Phényl éthanal & 1053 & 10.85 & 13.28 \\
\hline 1 propylbenzene & 1056 & - & 10.02 \\
\hline 2-methyoxyphénol & 1085 & 2.07 & 0.03 \\
\hline methyl benzoyl formate & 1073 & - & 0.22 \\
\hline O-methoxyphenyl acétate & 1095 & - & 0.07 \\
\hline Thozone & 1102 & 0.48 & - \\
\hline 2,6 dimithyleyclohexanol & 1107 & - & 0.75 \\
\hline 2-indanone & 1150 & 0.56 & - \\
\hline 3-Phenylprop 2-énal & 1157 & - & 1.30 \\
\hline Bornéol & 1162 & 1.39 & 0.65 \\
\hline Terpinen-4-ol & 1173 & - & 0.16 \\
\hline m-methylacétophone & 1181 & - & 0.12 \\
\hline a-terpinol & 1186 & 1.50 & - \\
\hline 2,2' dibutoxyéthylether & 1189 & - & 3.88 \\
\hline Verbenone & 1206 & 0.34 & 1.27 \\
\hline Benzothiazole & 1120 & 1.90 & 2.65 \\
\hline 2,5 diméthyle 3 enyl formate & 1226 & 0.40 & - \\
\hline 2-butylcyclohexanone none & 1260 & 0.071 & - \\
\hline
\end{tabular}

\begin{tabular}{|c|c|c|c|}
\hline 2 propylpiperidine & 1250 & - & 0.02 \\
\hline Thymol & 1300 & 1.84 & - \\
\hline 2 methoxy-4-vinylphénol & 1310 & 36.51 & - \\
\hline 4-hydroxy 2-methylacitophone & 1311 & - & 15.60 \\
\hline 1,4 diéthoxy-benzené & 1341 & - & 0.58 \\
\hline Eugénol & 1353 & 0.75 & 0.18 \\
\hline y dicalactone & 1358 & 0.30 & 0.45 \\
\hline $3,5,5$ trimethy hexan 1 & 1364 & 0.25 & - \\
\hline Vanilline & 1395 & - & 3.16 \\
\hline y Cadinene & 1422 & - & 0.06 \\
\hline $\begin{array}{l}\text { Esterméthylique de l'acide } 9 \text { oxo } \\
\text { nonanoique }\end{array}$ & 1430 & - & 0.29 \\
\hline$\beta$ ionome & 1480 & - & 0.17 \\
\hline$\beta$ cubebene & 1475 & - & 0.51 \\
\hline 4,6 de tert butyl 2 méthyl phénol & 1506 & 0.28 & 0.88 \\
\hline Benzophénone & 1619 & 0.14 & 0.21 \\
\hline T murolol & 1635 & - & 0.16 \\
\hline a cadinol & 1645 & - & 0.30 \\
\hline 3,5 di-tertbutyl 4 hydrobenzaldchyde & 1556 & 0.35 & 0.65 \\
\hline Icosanol & 1786 & - & 0.10 \\
\hline $2,6,10,15$ tetraméthylheptadécane & 1791 & - & 0.42 \\
\hline Tetradicanamide & 1814 & - & 0.01 \\
\hline 13 epimanol & 2042 & 0.02 & - \\
\hline Linolèate de methyle & 2086 & - & 1.98 \\
\hline Isotréatate de méthyle & 2119 & - & 0.20 \\
\hline Déamide & 2351 & 0.13 & 26.07 \\
\hline Squatène & 2812 & 0.59 & - \\
\hline Isopropyl palmitate & 2018 & 0.21 & - \\
\hline Nom identifie & 1266 & 0.32 & - \\
\hline Indolizine & 1290 & 0.32 & - \\
\hline Non identifiée & 1338 & 0.49 & - \\
\hline Diheptylèther & 1041 & - & 0.98 \\
\hline Camphre & 1140 & 1.17 & - \\
\hline Indolizine & 1290 & 0.32 & - \\
\hline \multicolumn{4}{|l|}{ DMSO=Dimethyl sulfoxide } \\
\hline
\end{tabular}

Table 2: Composition of Pistacia volatile extracts Pistacia lentiscus. 
Citation: Abdelkader M, Bouyahia Naima B, Boudiaf Nassima B (2017) Study of the Composition of the Volatile Fraction of the Pistacia lentiscus.

\section{Conclusion}

The chromatographic analysis of both extracts allowed us to identify the volatile fraction obtained from Pistacia lentiscus oil extract. The detected molecules have different chemical and physical characteristics, alcohols, aldehydes, ketones and nitrogen compounds.

The predominance within the hexane extract fraction is for alcohols, aldehydes and ketones, then are dominant in DMSO extract. Oleamide is a typical component of DMSO extract.

The vanillin is an aroma which has a peach note in DMSO extract with a salient relative rate. When encountering this identified and composed panoply, it is important to assign those that bestow typicality to the fraction volatile aroma.

The information obtained on the various substances could perhaps serve in particular studies on the sensory characterization using CPGolfactometrie which would be an interesting alternative. Forthcoming, this evaluation would serve as a main object of publication in your paper.

\section{References}

1. Luczel P, Santa S (1965) New Flora of Algeria and the southern desert regions. CNRS, pp: 31-40.

2. Labra M, Grassi F, Bardini M, Imazio S, Guiggi A, et al. (2003) Genetic relationships in Opuntia Mill genus (Cactaceae) detected by molecular marker. Plant Sci 165: 1129-1136.
3. Veselý J, Havliček L, Strnad M, Blow JJ, Donella M, et al. (1994) Inhibition of cyclin-dependent kinases by purine analogues. The FEBS J 224: 771-786.

4. Adams RP (2001) Identification of Essentials oils components by Gas chromatography/quadripole mars spectroocopys. Allured Ed Carol Stream, pp: 454.

5. Hamouchi M, Hamouchi I, Zoubdi M (2001) Chemical and antimicrobial properties of essential oil Five Morocan Pinacée essential oil Research. The FEBS J 3: 298-302.

6. Fiske AP (2004) Four modes of constituting relationships: Consubstantial assimilation; space, magnitude, time, and force; concrete procedures; abstract symbolism. Relational Models theory. A Contem Overvi 22: 61-146.

7. Flath RA, Takahashi JM (1978) Volatile constituents of prickly pear (Opuntia ficus indica Mill., de Castilla variety). J Agricult Food Chem 26: 835-837.

8. Clevenger JF (1928) Apparatus for the determination of volatile oil. J Am Pharm Assoc 17: 346-351.

9. Jennings W (2012) Qualitative analysis of flavor and fragrance volatiles by glass capillary gas chromatography. New York University Press, Elsevier.

10. Vernin G, Lagest C, Ghiglione C, Dahia M, Parkanyl R (1999) GC/MS Analysis of the volatile constituents of the essential oils of Pituranthos scoparius Bent et Hook, from Algeria I. Essent Oil Res 11: 673-676.

11. Gueldner RC, Wilson DM, Heidt AR (1985) Volatile compounds inhibiting Aspergillus flavus. J Agricult Food Chem 33: 411-413. 